\title{
(2) OPEN ACCESS \\ Recurrent chronic thromboembolic disease despite optimal anticoagulation in setting of recent COVID-19 infection
}

\author{
Vittorio Romeo Terrigno, ${ }^{1}$ Daniel Anthony Ricketti, ${ }^{1}$ Pranav Patel, ${ }^{2}$ Satyajeet Roy ${ }^{3}$
}

\begin{abstract}
'Internal Medicine, Cooper University Health Care, Camden, New Jersey, USA

${ }^{2}$ Cardiology, Cooper University Health Care, Camden, New Jersey, USA

${ }^{3}$ Internal Medicine, Cooper University Hospital, Cherry Hill, New Jersey, USA
\end{abstract}

Correspondence to Dr Vittorio Romeo Terrigno; terrigno-vittorio@cooperhealth. edu

Accepted 7 January 2021

Check for updates

(c) BMJ Publishing Group Limited 2021. Re-use permitted under CC BY-NC. No commercial re-use. See rights and permissions. Published by BMJ.

To cite: Terrigno VR, Ricketti DA, Patel P, et al. BM Case Rep 2021:14:e238733. doi:10.1136/bcr-2020238733

\section{SUMMARY}

We present a case of a 38-year-old man with a history of chronic thromboembolic pulmonary hypertension on therapeutic anticoagulation and recent hospitalisation for COVID-19 disease who was hospitalised for recurrent acute pulmonary embolism despite therapeutic anticoagulation with warfarin (International Normalized Ratio (INR) of 3.0). Our case highlights the hypercoagulable state associated with COVID-19 disease and the absence of standardised approaches to anticoagulation treatment for this population.

\section{BACKGROUND}

The ongoing COVID-19 pandemic continues to be an emerging and rapidly evolving disorder.

Recent studies have described a link between COVID-19, coagulopathy and venous thromboembolism. ${ }^{12}$ A limited prospective cohort study examining autopsies of patients with COVID-19 found evidence of thrombotic disease in $58 \%$ of the patients. ${ }^{3}$ A subsequent study looking at 184 patients in the intensive care unit found a $31 \%$ incidence of thrombotic complications despite patients being on standard dose venous thromboembolism prophylaxis. ${ }^{4}$

Another study from the University of Science and Technology in Wuhan, China classified patients into a high-risk group based on their sepsis-induced coagulopathy (SIC) score. This scoring system includes values such as prothrombin time (PT), platelet count and sequential organ failure assessment. The study found that the patients in the elevated SIC score group who were anticoagulated with heparin had a decrease in mortality.

We present a case of recurrent pulmonary embolism (PE) in the setting of COVID-19 disease while the patient was on therapeutic anticoagulation. The purpose of this paper is to bring attention to the hypercoagulable state associated with COVID-19 disease and the challenges with treatment of a unique subset of patients who develop recurrent thrombosis despite therapeutic anticoagulation.

\section{CASE PRESENTATION}

A 38-year-old man presented to our hospital with a 3-hour history of abdominal pain and nausea. During the initial encounter, the patient denied having chest pain, shortness of breath, palpitations, cough or haemoptysis. Two weeks prior to presentation, he was discharged from the hospital after a 3-week-long hospital course for COVID-19 pneumonia, which required endotracheal intubation and ventilatory support. While intubated with active COVID-19 pneumonia, a CT PE (CTPE) study showed no evidence of PE. His previous medical history was significant for PE at the age of 16. His PE was thought to be provoked in the setting of trauma for which he was treated with 6 months of warfarin. Following 6 months of anticoagulation, he remained well until age 30 , when he was diagnosed with a second PE and chronic thromboembolic pulmonary hypertension. This diagnosis was made at a pulmonary hypertension centre where the patient also underwent thromboendarterectomy and was then started on long-term warfarin therapy with regular International Normalized Ratio (INR) checks and close follow-up visits. His hypercoagulable work-up after the second PE was negative (table 1). He reported that he was reported with his medication regimen, and his INR levels confirmed that he was consistently in the therapeutic range. On presentation to our hospital, the patient's blood pressure was $129 / 86 \mathrm{~mm} \mathrm{Hg}$, heart rate was 99 bpm, respiratory rate was $16 / \mathrm{min}$ and temperature was $100.4^{\circ} \mathrm{F}$. His physical examination was remarkable for obesity and moderate bilateral symmetrical lower extremity oedema. He remained haemodynamically stable throughout his hospital course.

\section{INVESTIGATIONS}

The patient had an unremarkable basic metabolic panel, negative high sensitivity troponins, platelets within normal limit, and had an elevated white cell count of $12.94 \times 10^{9} / \mathrm{L}$. His INR remained in the therapeutic range throughout his hospital course: PT was elevated to $34.7 \mathrm{~s}$ consistent with warfarin use, and PTT was normal at $37.4 \mathrm{~s}$. A CT scan of his abdomen did not show any abnormalities in the abdomen but did show an incidental finding of a possible filling defect within a partially imaged dilated descending right pulmonary artery. Considering the incidental finding on abdominal imaging dedicated chest imaging with a CTPE was obtained, which showed a large filling defect within the descending right main pulmonary artery consistent with thromboembolism (figure 1). This filling defect was not visualised at the time of patient's initial admission while being treated for active COVID-19 pneumonia (images not available, only written report) and was not evident on studies prior to the patient's COVID-19 infection (figure 2). Given the significant dilation of his pulmonary arteries, an echocardiogram was performed. The 


\begin{tabular}{|c|c|}
\hline Laboratory test & Result \\
\hline Cardiolipin antibody & Negative \\
\hline Antithrombin III & $92 \%$ (within normal limits) \\
\hline Factor V Leiden mutation & Not identified \\
\hline Protein C level & $147 \%$ (within normal limits) \\
\hline Protein S level & $\begin{array}{l}58 \% \text { (decreased but the lab was obtained while } \\
\text { patient was already started on warfarin) }\end{array}$ \\
\hline Factor II gene mutation & Not identified \\
\hline Dilute Russel's viper venom time & $32.9 \mathrm{~s}$ (within normal limits) \\
\hline
\end{tabular}

$\mathrm{PE}$, pulmonary embolism.

echocardiogram showed a dilated right atrium (RA) with bowing of the interatrial septum to the left suggestive of increased RA pressure $(8 \mathrm{~mm} \mathrm{Hg})$ as well as a severely dilated right ventricle with severely reduced systolic function (figure 3). This study also demonstrated diastolic and systolic Left Ventricular septal flattening consistent with pressure and volume overload with a dilated inferior vena cava. Lower extremity Doppler ultrasounds, although limited by body habitus, were performed and did not demonstrate a deep vein thrombosis.

\section{DIFFERENTIAL DIAGNOSIS}

On admission, the patient's main report was of periumbilical abdominal pain and nausea. Given his fever and elevation in white cell count, an abdominal infection was considered. His white cell count resolved spontaneously by day 2 of his hospitalisation. In addition to this, he was without diarrhoea, the Clostridium difficile screen was negative, blood cultures were negative, and CT abdomen and pelvis did not demonstrate an infectious source. Given his recent hospitalisation requiring intubation, we thought that he may be suffering from stress ulcers. We investigated this further, but the patient had no signs of gastrointestinal bleeding. He had a negative faecal occult blood test and had stable haemoglobin values through his hospital course. Another consideration was acute pancreatitis, but this was ruled out due to normal serum amylase, normal serum lipase and normal appearance of the pancreas on CT imaging of the abdomen. Ultimately the patient's abdominal symptoms, fevers and leukocytosis resolved without any intervention. His CT abdomen showed a potential filling defect in the pulmonary artery. The findings changed our course of thinking, and a PE was ruled in as the CTPE study showed a large filling defect within the right main pulmonary artery. Although therapeutically anticoagulated, other causes of venous thromboembolism

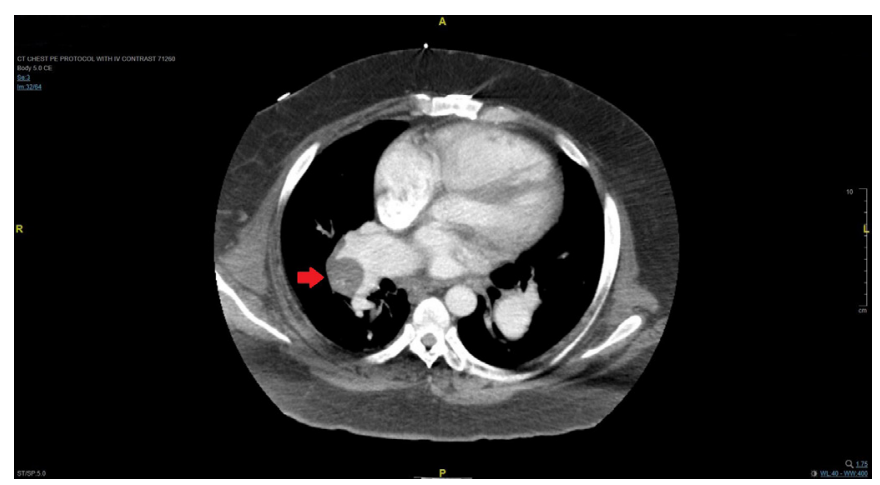

Figure 1 CT chest during current presentation showing a large filling defect within the descending right main pulmonary artery consistent with thromboembolism. Defect indicated by red arrow.

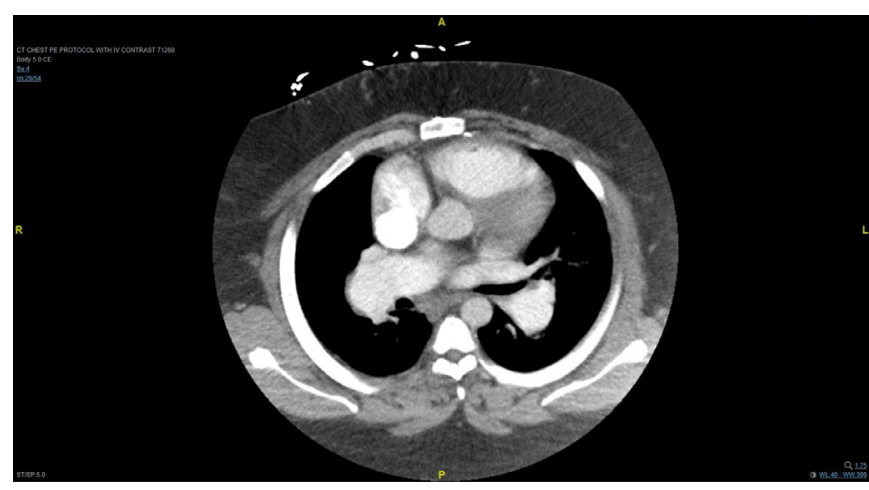

Figure $2 \mathrm{CT}$ chest from 1 month prior to second admission showing lack of pulmonary emboli.

(VTE) were considered including malignancy, other inflammatory states, obesity and recent immobilisation during hospitalisation. Sequela of the patient's recent COVID-19 infection may have contributed to patient's presentation and initial laboratory findings.

\section{TREATMENT}

In the hospital, the patient was treated with intranasal oxygen, supportive care, and was transiently on unfractionated intravenous heparin therapy while the consideration of anticoagulation failure was being discussed. Due to the patient's morbid obesity and the lack of data on the efficacy and safety of Direct Oral Anticoagulants (DOACs) in obese patients, a DOAC was not considered as a therapeutic option. Additionally, the patient was not thought to be a candidate for subcutaneous enoxaparin therapy due to his high dose requirement calculation based on his obesity. Following extensive discussions between the care teams and the patient, a decision was ultimately made to continue on warfarin with a slightly higher INR target range. In addition to this, the patient was advised to follow closely with the haematology department for future consideration of enoxaparin therapy with monitoring of Factor Xa levels, after adequate weight loss.

\section{OUTCOME AND FOLLOW-UP}

After a multidisciplinary team weighed the pros and cons of Novel Oral Anticoagulants and enoxaparin therapy with the patient, he decided to remain on warfarin therapy with close

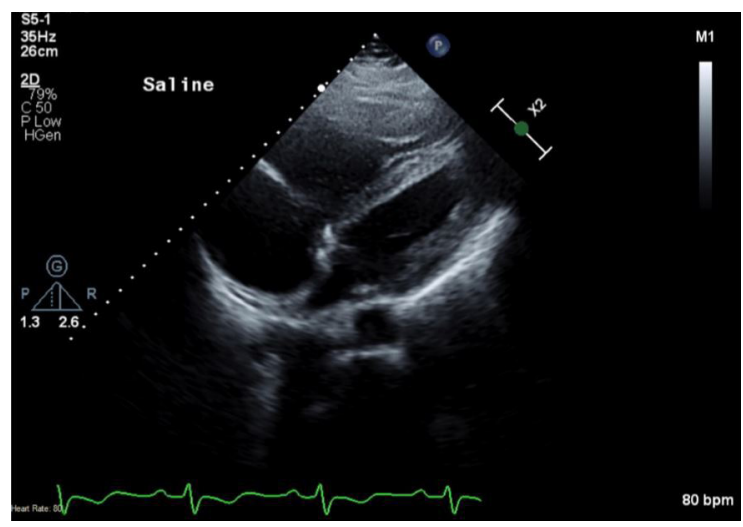

Figure $32 \mathrm{D}$ echocardiogram showing dilated right atrium (RA) with bowing of the interatrial septum to the left suggestive of increased RA pressure, severely dilated right ventricle with severely reduced systolic function. 
follow-up. Multiple postdischarge attempts have been made to contact the patient for a follow-up visit but he has not responded to our follow-up reminders.

\section{DISCUSSION}

Patients with COVID-19 disease who have confirmed VTE should be started on full dose anticoagulation unless otherwise contraindicated. Current guidelines do not address treatment of patients with acute VTE in the setting of COVID-19. The current International Society on Thrombosis and Hemostasis (ISTH) guidelines do not address treatment of patients with acute VTE in the setting of COVID-19 disease. ${ }^{6}$ The guidelines from ISTH report the advantages of low-molecular weight heparin (LMWH) therapy when used as an inpatient and direct oral anticoagulants when used as an outpatient. Specific studies appear to show an improved prognosis in patients with COVID-19 who are treated with $\mathrm{LMWH}$, possibly due to its anti-inflammatory effects. ${ }^{5}$ Heparinoids have previously demonstrated both antiinflammatory and antiviral properties, which may explain a benefit in patients with COVID-19. ${ }^{7}$ Despite these benefits associated with heparinoids, the patient's obesity made dosing difficult due to the distribution and metabolism of the drug. Also, lack of clear guidelines for treatment failure in the setting of COVID-19 leads to the decision to continue the patient on warfarin. Our patient had a negative hypercoagulable work-up following his second VTE. While our patient has several risk factors including obesity, history of previous PE and a history of a recent prolonged hospital course, he was adequately treated with evidence of therapeutic anticoagulation, which had kept him free from developing a PE for about 8 years prior to his presentation. We postulate that the recent COVID-19 infection had been the contributing risk factor given the present literature on COVID-19 and its association with hypercoagulable states.

Learning points

- Recurrent venous thromboembolism (VTE) can occur in patients on therapeutic anticoagulation for a history of VTE after COVID-19 infection.

- Clinical trials are ongoing to determine optimal anticoagulation strategies in patients with VTE in the setting of COVID-19.

- Effective and safe modality of anticoagulation in obese patients with recent VTE and COVID-19 disease is yet to be developed.
On presentation to our hospital, the patient's INR was 3.0. Despite this, his CTPE study demonstrated a large filling defect within the descending right main pulmonary artery consistent with thromboembolism. Our study further highlights the need for new therapeutic anticoagulation management and parameters in not only critically ill patients with COVID-19 disease but also in patients with COVID-19 disease and a history of previous thrombosis. A number of randomised control trials are ongoing to determine an optimal anticoagulation regimen in patients with COVID-19 disease.

\section{Twitter Daniel Anthony Ricketti @DrRicketti}

Contributors VRT: responsible for the planning and design of the case report as well as acquisition of data. Also responsible for the written portion of the case report following the acquisition of data. DAR: responsible for the planning and design of the case report as well as acquisition of data. Also responsible for the written portion of the case report following the acquisition of data. PP: responsible for the planning and design of the case report. Also responsible for the written portion of the case report following the acquisition of data. SR: responsible for contributing to the write up as well as formatting and editing of the case report. Helped to organise and plan the case report design.

Funding The authors have not declared a specific grant for this research from any funding agency in the public, commercial or not-for-profit sectors.

Competing interests None declared.

\section{Patient consent for publication Obtained.}

Provenance and peer review Not commissioned; externally peer reviewed.

Open access This is an open access article distributed in accordance with the Creative Commons Attribution Non Commercial (CC BY-NC 4.0) license, which permits others to distribute, remix, adapt, build upon this work non-commercially, and license their derivative works on different terms, provided the original work is properly cited and the use is non-commercial. See: http://creativecommons.org/ licenses/by-nc/4.0/.

\section{REFERENCES}

1 Chen N, Zhou M, Dong X, et al. Epidemiological and clinical characteristics of 99 cases of 2019 novel coronavirus pneumonia in Wuhan, China: a descriptive study. Lancet 2020;395:507-13

2 Porfidia A, Pola R. Venous thromboembolism in COVID-19 patients. J Thromb Haemost 2020;18:1516-7.

3 Wichmann D, Sperhake JP, Lütgehetmann M. Autopsy findings and venous thromboembolism in patients with COVID-19. Ann Intern Med 2020:M20-3.

4 Klok FA, Kruip MJHA, van der Meer NJM, et al. Incidence of thrombotic complications in critically ill ICU patients with COVID-19. Thromb Res 2020;191:145-7.

5 Tang N, Bai H, Chen X, et al. Anticoagulant treatment is associated with decreased mortality in severe coronavirus disease 2019 patients with coagulopathy. J Thromb Haemost 2020;18:1094-9.

6 Spyropoulos AC, Levy JH, Ageno W, et al. Scientific and standardization Committee communication: clinical guidance on the diagnosis, prevention, and treatment of venous thromboembolism in hospitalized patients with COVID-19. J Thromb Haemost 2020;18:1859-65.

7 Mulloy B, Hogwood J, Gray E, et al. Pharmacology of heparin and related drugs. Pharmacol Rev 2016:68:76-141.

Copyright 2021 BMJ Publishing Group. All rights reserved. For permission to reuse any of this content visit

https://www.bmj.com/company/products-services/rights-and-licensing/permissions/

BMJ Case Report Fellows may re-use this article for personal use and teaching without any further permission.

Become a Fellow of BMJ Case Reports today and you can:

- Submit as many cases as you like

- Enjoy fast sympathetic peer review and rapid publication of accepted articles

- Access all the published articles

- Re-use any of the published material for personal use and teaching without further permission

Customer Service

If you have any further queries about your subscription, please contact our customer services team on +44 (0) 2071111105 or via email at support@bmj.com.

Visit casereports.bmj.com for more articles like this and to become a Fellow 